\title{
Dermatophagoides pteronyssinus Antigen IgE Antibody Measurement
}

National Cancer Institute

\section{Source}

National Cancer Institute. Dermatophagoides pteronyssinus Antigen IgE Antibody

Measurement. NCl Thesaurus. Code C130134.

A measurement of the Dermatophagoides pteronyssinus antigen IgE antibody in a biological specimen. 